Tropical Journal of Pharmaceutical Research September 2015; 14 (9): 1667-1672

ISSN: 1596-5996 (print); 1596-9827 (electronic)

(C) Pharmacotherapy Group, Faculty of Pharmacy, University of Benin, Benin City, 300001 Nigeria.

All rights reserved.

Available online at http://www.tjpr.org

Original Research Article

http://dx.doi.org/10.4314/tjpr.v14i9.17

\title{
Charge-Transfer Reaction of Cediranib with 2,3-Dichloro- 3,5-dicyano-1,4-benzoquinone: Spectrophotometric Investigation and Use in Development of Microwell Assay for Cediranib
}

\author{
Nasr Y Khalil, Tanveer A Wani, Ibrahim A Darwish* and Ibrahim S Assiri \\ Department of Pharmaceutical Chemistry, College of Pharmacy, King Saud University, PO Box 2457, Riyadh 11451, Saudi
} Arabia

${ }^{*}$ For correspondence: Email: idarwish@ksu.edu.sa; Tel: +966-114677348; Fax: +966-114676220

Received: 13 February 2015

Revised accepted: 1 August 2015

\begin{abstract}
Purpose: To investigate the charge-transfer (CT) reaction between cediranib (CRB) and 2, 3 - dichloro5, 6- dicyano -1, 4 - benzoquinone (DDQ) and employment of the reaction as a basis for the development of a novel 96 - microwell spectrophotometric assay for CRB.

Method: The reaction of CRB and DDQ was investigated in different solvents of varying dielectric constant and polarity index The reaction resulted in the formation of a red-colored product. Spectrophotometric investigations confirmed that the reaction proceeded through to the formation of a (CT) complex.

Results: The molar absorptivity of the CT complex was linearly correlated with the dielectric constant and polarity index of the solvent; the correlation coefficients were 0.801 and 0.858 , respectively. The association constant of the complex was $0.5 \times 10^{3} \mathrm{~L} \mathrm{~mol}^{1}$ in 2-propanol. The reaction conditions were optimized for the development of the microwell assay for CRB. The assay limits of detection and quantitation were 6.8 and $20.6 \mu \mathrm{g} / \mathrm{well}$, respectively. The assay was validated as per the guidelines of the International Conference on Harmonization (ICH) and successfully applied to the analysis of CRB in its bulk and dosage forms with good accuracy and precision.

Conclusion: The developed assay has high throughput and consumed minimum volume of organic solvent; thus, it reduces the exposure of the analysts to the toxic effects of organic solvents, and should significantly lower the analysis cost.
\end{abstract}

Keywords: Cediranib, 2,3-dichloro-3,5-dicyano-1,4-benzoquinone, Charge-transfer reaction, Spectrophotometry, Microwell assay, High throughput analysis.

Tropical Journal of Pharmaceutical Research is indexed by Science Citation Index (SciSearch), Scopus, International Pharmaceutical Abstract, Chemical Abstracts, Embase, Index Copernicus, EBSCO, African Index Medicus, JournalSeek, Journal Citation Reports/Science Edition, Directory of Open Access Journals (DOAJ), African Journal Online, Bioline International, Open-J-Gate and Pharmacy Abstracts

\section{INTRODUCTION}

Cediranib (CRB, Fig 1) is a novel small-molecule; potent inhibitor of vascular endothelial growth factor (VEDF) receptor tyrosine kinases [1-3]. Extensive literature survey revealed that only one liquid chromatography-mass spectrometric method was available for determination of CRB in biological fluids [4]. This fact promoted our interest in the development of a new method for quality control (QC) of CRB.

The charge-transfer (CT) reaction between the electron-donating and electron-accepting molecules has considerable importance in different fields of chemistry [5-8]. CT reactions 
are generally associated with the formation of intensely colored CT complexes, which usually absorb radiations; consequently, a new light absorption band occurs at much longer wavelength than in the spectra of the CT complex components [9]. The rapid formation of these complexes leads to their widespread utility in the development of spectrophotometric methods for analysis of many pharmaceutical molecules [10] and extensive studies involving CT reactions have been conducted [10 - 12]. The benzoquinone derivatives have $\pi$-orbitals of the benzoquinone ring, which have electronaccepting ability. This ability increases with the introduction of electron-withdrawing groups like chloro-, nitro-, cyano, etc., on the benzoquinone ring [13]. These groups have strong electronegativity and large Hammett constants [14]. 2, 3 - dichloro- 5, 6- dicyano -1, 4 benzoquinone (DDQ, Fig 1) acts as a strong $\pi-$ electron acceptor in studying the CT reactions of electron donors [15].

The present study was devoted to the investigation of the CT reaction between CRB and DDQ and employment of the reaction as a basis in the development of a novel 96 microwell high throughput spectrophotometric assay for CRB.

\section{EXPERIMENTAL}

\section{Chemicals and materials}

Cediranib (CRB) standard was obtained from Weihua Pharma Co. Ltd. (Zhejiang, China) and was used as received; the purity of the investigated compound was > $99 \%$. DDQ Sigma-Aldrich Corporation, (St. Louis, MO, USA). Solvents and excipients were of analytical grade (Fisher Scientific, California, CA, USA).

\section{Preparation of standard CRB solutions}

Into a $5 \mathrm{ml}$ calibrated flask, $10 \mathrm{mg}\left(2.22 \times 10^{-5}\right.$ mole) of CRB was accurately weighed, dissolved in $2 \mathrm{ml}$ methanol, and completed to volume with the same solvent. This stock solution $(4.44 \times$ $10^{-3} \mathrm{~mol} \mathrm{~L}^{-1}$ ) was diluted with the appropriate solvent to obtain CRB concentrations suitable for the corresponding study.

\section{Determination of association constant}

Series of CRB solutions $\left(0.89 \times 10^{-4}-5.5 \times 10^{-4}\right.$ $\mathrm{mol} \mathrm{L}^{-1}$ ) were mixed with $\mathrm{DDQ}$ solution of a fixed concentration $\left(4.4 \times 10^{-3} \mathrm{~mol} \mathrm{~L}^{-1}\right)$; both CRB and DDQ solutions were prepared in 2 - propanol as this solvent gave the highest readings and was not harmful to the microwell-plate transparency. These mixed solutions were allowed to reach equilibrium ( $\sim 5 \mathrm{~min})$ at room temperature $(25 \pm 2$ $\left.{ }^{\circ} \mathrm{C}\right)$. The absorbance of the solutions was measured at $460 \mathrm{~nm}$ against reagent blanks treated similarly. The measurements were conducted on UV-1601 PC double-beam ultraviolet-visible spectrophotometer (Shimadzu, Kyoto, Japan).

\section{Preparation of CRB-containing dosage form sample solution}

An accurately weighed amount $(45 \mathrm{mg})$ of CRB was mixed with the excipients: microcrystal-line<smiles>COc1cc2c(Oc3ccc4[nH]c(C)cc4c3F)nncc2cc1OCCCN1CCCC1</smiles>

Cediranib (CRB): 4-[(4-fluoro-2-methyl-1H-indol-5-yl) oxy]-6-methoxy-7[3-(pyrrolidin-1-yl)propoxy]quinazoline<smiles>O=c1c(Cl)c(Cl)c(=O)c(=O)c1=O</smiles>

DDQ: 2,3-Dichloro-3,5-dioyano-1,4-benzoquinone

Figure 1: The chemical structure and chemical names of cediranib (CRB) and 2, 3 - dichloro- 5, 6- dicyano -1, 4 benzoquinone $(\mathrm{DDQ})$ 
cellulose (50 mg), colloidal silicon dioxide (10 $\mathrm{mg}$ ), anhydrous dibasic calcium phosphate (5 $\mathrm{mg}$ ), sodium starch glycolate (5 mg), and magnesium stearate (5 mg). The laboratoryprepared sample was dissolved in $5 \mathrm{ml}$ of methanol, swirled and sonicated for $5 \mathrm{~min}$, and filtered. The first portion of the filtrate was rejected, and a measured volume of the filtrate was diluted with methanol to yield CRB concentrations in the range of $100-1000 \mu \mathrm{g} / \mathrm{ml}$. These samples were analyzed by the proposed assay applying the microwell assay procedure.

\section{Microwell assay procedure}

Accurately measured aliquots $(100 \mu \mathrm{L})$ of the standard or sample solution containing varying amounts of CRB $(100-1000 \mu \mathrm{g} / \mathrm{mL})$ were transferred into wells of 96 - microwell assay plates (Corning/Costar Inc., Cambridge, USA). Solutions were dispensed by adjustable 8 channel - pipette (Sigma Chemical Co., St. Louis, $\mathrm{MO}$, USA). One hundred microliters of DDQ solution $(0.1 \%$, w/v) was added, and the reaction was allowed to proceed at room temperature (25 $\pm 2{ }^{\circ} \mathrm{C}$ ) for $5 \mathrm{~min}$. The absorbances of the resulting solutions were measured at $460 \mathrm{~nm}$ by the microwell-plate reader (ELx 808, Bio-Tek Instruments Inc. Winooski, USA) empowered by Gen5 software (provided with the instrument). Blank wells were treated similarly except $100 \mu \mathrm{L}$ of methanol was used instead of the sample, and the absorbances of the blank wells were subtracted from those of the sample wells.

\section{RESULTS}

\section{Absorption spectral characteristics}

The absorption spectrum of CRB solution $(5.5 \times$ $10^{-4} \mathrm{~mol} \mathrm{~L}^{-1}$, in methanol) was recorded. It was obvious from the spectrum that CRB exhibited a maximum absorption peak $\left(\lambda_{\max }\right)$ at $320 \mathrm{~nm}$. CRB solution $\left(5.5 \times 10^{-4} \mathrm{M}\right)$ was mixed with $\mathrm{DDQ}$ solution $\left(4.4 \times 10^{-3} \mathrm{~mol} \mathrm{~L}^{-1}\right)$, and the interaction of $\mathrm{CRB}$ with DDQ was allowed to proceed at room temperature $\left(25 \pm 2{ }^{\circ} \mathrm{C}\right)$, and the absorption spectrum of the reaction mixture was recorded against DDQ reagent blank solution. A red-colored product was obtained showing absorption maximum at $460 \mathrm{~nm}$, and the reaction went to completion very rapidly.

\section{Effect of solvent on the interaction of CRB with DDQ}

The interaction of CRB with DDQ was allowed to proceed in different solvents of varying dielectric constants and polarity indices and the absorption spectra were recorded. The molar absorptivity $(\mathcal{E})$ was determined in each solvent; the obtained values are given in Table 1.

\section{Association constant for CRB-DDQ CT complex}

The association constant was evaluated at room temperature $\left(25 \pm 2{ }^{\circ} \mathrm{C}\right)$ and at the $\lambda_{\max }$ of $\mathrm{CRB}$ $\mathrm{DDQ}$ complex (in 2-propanol as this solvent gave the highest reading and did not affect the transparency of the microwell of the assay plate, as acetrontrile did) using the Benesi-Hildebrand equation (Equation 1) [19]:

$A_{o} / A^{A D}=1 / \varepsilon^{A D}+1 / K_{c}^{A D} \cdot \varepsilon^{A D} \times 1 / D_{0}$

where $\left[A_{\circ}\right]$ is the molar concentration of the acceptor (DDQ); $\left[D_{0}\right]$ is the molar concentration of the donor (CRB); $A^{A D}$ is the absorbance of the complex formed at the $\lambda_{\text {max }} ; \varepsilon^{A D}$ is the molar absorptivity of the complex; $\mathrm{K}_{\mathrm{c}}{ }^{\mathrm{AD}}$ is the association constant of the complex $\left(\mathrm{L} \mathrm{mol}^{-1}\right)$. Upon plotting the values $\left[A_{0}\right] / A^{A D}$ against $I /\left[D_{0}\right]$, a straight line was obtained, from which the association constant, correlation coefficient, and the molar absorptivity $(\varepsilon)$ of the CRB-DDQ complex were calculated. The intercept of the fitting line corresponded to $1 / \varepsilon^{A D}$ and the association constant was calculated from the slope value of the line and the derived value of $\varepsilon^{A D}$. The molar absorptivity and association constant of the complex (in 2-propanol) were found to be $1 \times 10^{3} \mathrm{~L} \mathrm{~mol}^{-1} \mathrm{~cm}^{-1}$ and $0.5 \times 10^{3} \mathrm{~L}$ $\mathrm{mol}^{-1}$, respectively. The standard free energy change $\left(\Delta \mathrm{G}^{\circ}\right)$ of the CT complex was calculated and found to be $3.7 \times 10^{3} \mathrm{kcal} \mathrm{mol}^{-1}$.

\section{Optimization of assay conditions}

The optimization of experimental conditions for carrying out the reaction in the 96-microwell assay plate was investigated by altering each reaction variable in turn while keeping the others constant. The reaction was carried out in methanol and all the measurements were carried out by the plate reader at $460 \mathrm{~nm}$. The studied conditions were: concentration of DDQ reagent, reaction time, and temperature. The studied range of these conditions and the optimum value that was selected for the assay development are given in Table 2.

It is worth mentioning that methanol was considered as optimum solvent for carrying out the reaction in the microwell assay plates although acetonitrile gave the highest $\varepsilon$ value 
Table 1: Effect of solvents on the position and intensity of absorption of the reaction mixtures of CRB with DDQ

\begin{tabular}{|c|c|c|c|}
\hline & \multicolumn{2}{|c|}{ Solvent } & \multirow[t]{2}{*}{$\varepsilon\left(\times 10^{3}\right)$} \\
\hline Name & DEC $^{a}$ & $\mathbf{P I}^{\mathbf{b}}$ & \\
\hline Acetonitrile & 37.5 & 5.8 & 3.28 \\
\hline Methanol & 32.7 & 5.1 & 2.87 \\
\hline Ethanol & 24.6 & 5.2 & 2.75 \\
\hline Acetone & 20.7 & 5.1 & 2.34 \\
\hline 2-Propanol & 19.9 & 3.9 & 2.24 \\
\hline Dichloromethane & 10.5 & 3.5 & 2.03 \\
\hline Dichloroethane & 9.1 & 3.1 & 0.51 \\
\hline Toluene & 2.4 & 2.4 & 0.22 \\
\hline Chloroform & 2.2 & 4.8 & 0.10 \\
\hline
\end{tabular}

${ }^{a} D E C=$ dielectric constant; values were obtained from reference $18 ;{ }^{b} \mathrm{Pl}=$ Polarity index; values were obtained from reference $19:^{\circ} \varepsilon=$ molar absorptivity; values are expressed as $L \mathrm{mo}^{1} \mathrm{~cm}^{-1}$

(Table 1). This was because of the negative effect of acetonitrile on the transparency of the assay plate material.

\section{Validation and application of the assay}

Under the above mentioned optimum reaction conditions, the calibration curve for the analysis of CRB by the proposed assay was constructed. The regression equation for the results was derived using the least-squares method. Beer's law plot (10-concentration levels, $n=5)$ was linear in the range of $10-100 \mu \mathrm{g} /$ well. The calibration equation was: $A=0.0386+0.0089 \mathrm{C}(r=$ 0.9995), where $A, C$ and $r$ are the absorbance, concentration of $\mathrm{CRB}(\mathrm{mg} /$ well) and correlation coefficient, respectively (Table 3 ). The limits of detection (LOD) and quantitation (LOQ) were determined [25] using the formula: LOD or LOQ $=\mathrm{kSDa} / \mathrm{b}$, where $\mathrm{k}=3.3$ for LOD and 10 for $\mathrm{LOQ}, \mathrm{SDa}$ is the standard deviation of the intercept, and $b$ is the slope. The LOD and LOQ values were 6.8 and $20.6 \mu \mathrm{g} /$ well, respectively. The intra- and inter assay precisions were assessed at three CRB concentrations (20, 50 and $80 \mu \mathrm{g} /$ well). The relative standard deviation (RSD) values did not exceed $2 \%$, indicating good precision of the assay. This good level of precision was attributed to the accuracy of the volumes that were concomitantly dispensed in the microwells by multi-channel pipettes, and completeness of the reaction in a small volume $(200 \mu \mathrm{L})$. The high-precision property of the assay made it suitable for its routine application in QC laboratories for determination of CRB samples (bulk and dosage forms). In addition, the accuracy, robustness and ruggedness of the assay were evaluated and all the results were satisfactory as per the $\mathrm{ICH}$ guidelines [25]. A summary for the quantitative and validation parameters of the assay is given in Table 3 . The assay was applied to the analysis of CRBcontaining laboratory-made dosage forms. The mean percentage recovery, relative to the nominated amounts, obtained by the proposed assay was $98.23 \pm 2.58 \%$. This good recovery values indicated the reliability of the proposed assay for routine application for the accurate determination of $\mathrm{CRB}$ in pharmaceutical $\mathrm{QC}$ laboratories.

Table 3: Quantitative parameters for the analysis of CRB by the microwell spectrophotometric assay based on the CT reaction of CRB with $\mathrm{DDQ}$

\begin{tabular}{lc}
\hline Parameter & Value \\
\hline Linear range $(\mu \mathrm{g} /$ well $)$ & $10-100$ \\
Intercept & 0.0386 \\
Standard deviation of & 0.0184 \\
intercept & \\
Slope & 0.0089 \\
Standard deviation of & $3 \times 10^{-4}$ \\
slope & \\
Correlation coefficient & 0.9995 \\
LOD $(\mu \mathrm{g} /$ well) & 6.8 \\
LOQ $(\mu \mathrm{g} /$ well) & 20.6 \\
Precision $(\mathrm{RSD}, \%)$ & $<2$ \\
Accuracy $(\%)$ & $>98$ \\
\hline
\end{tabular}

Table 2: Optimization of experimental conditions for the microwell spectrophotometric assay for CRB based on its formation of colored CT complex with $D D Q$

\begin{tabular}{|c|c|c|}
\hline Condition & Studied range & Optimum \\
\hline DDQ conc. $(\%, w / v)$ & $0.02-0.2$ & 0.1 \\
\hline Solvent & Different ${ }^{a}$ & Methanol \\
\hline Reaction time (min) & $2-40$ & 5 \\
\hline Temperature $\left({ }^{\circ} \mathrm{C}\right)$ & $25-60$ & 25 \\
\hline$\lambda_{\max }(\mathrm{nm})$ & $400-650$ & 460 \\
\hline
\end{tabular}

${ }^{a}$ Solvents used as in Table 1

\section{DISCUSSION}

The results showed us that the absorption intensity of the new absorption maximum (460 $\mathrm{nm}$ ) increased with CRB concentrations in the interaction solution. This continuous increase in the absorbance of the new absorption band with 
(the reaction time and) $\mathrm{CRB}$ concentrations was indicative of the formation of CRB - DDQ product. The new absorption band was attributed to the complete electron transfer from CRB (D) to DDQ (electron acceptor; A) accompanied by the formation of colored radical acceptor anion (DDQ-) [16], which was formed by the dissociation of an original donor-acceptor (D - A) complex (equation 2).

$\mathrm{D}+\mathrm{A} \rightleftharpoons \underset{\text { complex }}{(\mathrm{D}-\mathrm{A}) \stackrel{\substack{\text { polar } \\ \text { solvent }}}{\mathrm{D}^{+}++\mathrm{A}^{-}} \text {radical ions }}$

The dissociation of the (D - A) complex was promoted by the high ionizing power of the polar solvent and the resulting peak in the absorption spectra of the reaction mixture were similar to the maxima of the radical anion of the acceptor obtained by the iodide reduction method [16].

The interaction in polar solvents with high dielectric constants (e.g. acetonitrile, methanol, ethanol, etc) produced CT complexes with $\varepsilon$ values higher than those produced in low-polar solvents with low dielectric constants (e.g. dichloromethane); however the reaction did not proceed at all in non-polar solvent (e.g. chloroform). The values of $\varepsilon$ correlated with both the dielectric constants [17] and polarity indices [18] of the solvents in which the reaction was performed; correlation coefficients were $(r)=$ 0.801 and 0.858 for dielectric constants and polarity indices, respectively. This was attributed to the complete electron transfer from CRB (electron donor; D) to DDQ (electron acceptor; A) that took place in the polar solvents. Among all the solvents tested, acetonitrile offered the highest $\varepsilon$ value. This was attributed to its high dielectric constant that promoted maximum yield of radical anion of $D D Q$, in addition to its high solvating power for both $\mathrm{DDQ}$ and CRB.

The relatively low value of the association constant was attributed to the common feature for CT complexes with $\pi$-acceptors because of the dissociation of the original donor-acceptor complex to the radical anion [9].

The standard free energy change $\left(\Delta G^{\circ}\right)$ of the $\mathrm{CT}$ complex is related to its association constant and it can be calculated by the following formula (equation 3 ):

$\Delta G^{\circ}=-2.303 R T \log K_{c}$

where $\Delta G^{\circ}$ is the standard free energy change of the complex $\left(\mathrm{kcal} \mathrm{mol}^{-1}\right), \mathrm{R}$ is the gas constant (1.987 calories degree/mole), $\mathrm{T}$ is the absolute temperature in Kelvin $\left({ }^{\circ} \mathrm{C}+273\right)$ and $\mathrm{K}_{\mathrm{c}}$ is the association constant of the complex ( $/ /$ mole).

Based on the aforementioned successful formation of a red-colored CT complex between $\mathrm{CRB}$ and $\mathrm{DDQ}$, the reaction was used as a basis for the development of CT-based photometric assay for the pharmaceutical quality control (QC) of CRB. The conventional CT-based photometric methods are not automated and consequently their analysis throughput is low, thus their applications in QC laboratories are limited. Moreover, these methods suffer from the consumption of large volumes of organic solvents, which leads to high analysis cost, and more importantly, the incidence of exposure of the analysts to the toxic effects of the organic solvents [19-23]. Therefore, the present study was devoted to employing the CT reaction of $\mathrm{CRB}$ in the development of novel photometric method with high analysis throughput that can reduce the consumption of organic solvents in the QC of CRB.

In previous studies, Darwish et al [24] successfully adopted a microwell plate reader equipped with photometric detection in the development of high-throughput photometric assays for measuring the active drug contents in pharmaceutical preparations. For these reasons, the present study was designed to employ this methodology for CRB; the reaction was carried out in 96 - microwell plates ( $200 \mu \mathrm{L}$ volume).

\section{CONCLUSION}

This is the first report on the description of the $\mathrm{CT}$ reaction between CRB and DDQ. The as-say provides a high analytical throughput that can facilitate the processing of a large number of samples in a relatively short time. This property is attributed to the use of multi-channel pipettes for efficient dispensing of the solutions, carrying out the analytical reaction in 96 - well plates (as reaction vessels), and measuring the color signals in the 96 wells at $\sim 30 \mathrm{~s}$ by the plate reader. In addition, the assay can reduce the consumption of organic solvents, thus reducing the exposure of analysts to the toxic effects of organic solvents, and will lead to lowering of analysis cost when the method employed in pharmaceutical quality control laboratories.

\section{ACKNOWLEDGEMENT}

The authors would like to extend their appreciation to the Deanship of Scientific Research at King Saud University for funding of 
this research through Research Group Project no. RGP-VPP-225.

\section{REFERENCES}

1. Wedge SR, Kendrew J, Hennequin LF, Valentine PJ, Barry ST, Brave SR, Smith NR, James NH, Dukes M, Curwen JO, et al. AZD2171: a highly potent, orally bioavailable, vascular endothelial growth factor receptor-2 tyrosine kinase inhibitor for the treatment of cancer. Cancer Res 2005; 65(10): 4389-4400.

2. Goss G, Shepherd FA, Laurie S, Gauthier I, Leighl N, Chen E, Feld R, Powers J, Seymour L. A phase I and pharmacokinetic study of daily oral cediranib, an inhibitor of vas-cular endothelial growth factor tyrosine kinases, in combination with cisplatin and gem-citabine in patients with advanced non-small cell lung cancer: a study of the National Cancer Institute of Canada Clinical Trials Group. Eur J Cancer 2009; 45(5): 782-788.

3. Martin-Liberal J, Benson C, Judson I: New drugs in sarcomas. Expert Opin Pharmacother 2014; 15(2): 221-229

4. Wang T, Oberoi RK, Elmquist WF. Determination of cediranib in mouse plasma and brain tissue using high-performance liquid chromatography-mass spectrometry. J Chromatogr B 2011; 879(32): 38123817

5. Pandeeswaran M, Elango KP Spectroscopic studies on the molecular complex of the drug atenolol with iodine. J. Solution Chem 2009; 38(12): 1558-1572.

6. Takahashi $K$, Horino $K$, Komura $T$, Murata $K$. Photovoltaic properties of porphyrin thin films mixed with o-chloranil. Chem Soc Jpn 1993; 66(3): 733-738.

7. Taboada P, Gutiérrez-Pichel M, Barbosa S, Attwood D, Mosquera V. Phys Chem Chem Phys 2003; 5(4): 703-709.

8. Pandeeswaran M, Elango KP. Spectroscopic and kinetic studies on the interaction of ketoconazole and povidone drugs with $D D Q$. Spectrochim Acta $\mathrm{A} \mathrm{Mol}$ Biomol Spectrosc 2008; 75(4): 1082-1088.

9. Foster R. Organic Charge-Transfer Complexes; Academic Press, New York, USA, 1969

10. áSbarbati Nudelman N. Reaction of 2, 4dinitrochlorobenzene with aniline: solvent effects and molecular complex formation. J Chem Soc Perkin Trans 1999; 2(8): 1627-1630.

11. Fakhroo AA, Bazzi HS, Mostafa A, Shahada $L$. Synthesis, spectroscopic and thermal structural investigations of the charge-transfer complexes formed in the reaction of 1-methylpiperidine with $\sigma$ - and $\pi$-acceptors. Spectrochim Acta A Mol Biomol Spectrosc 2010; 75 (1): 134-141.

12. Nayek M, Mukherjee A, Seal B. Study of a novel reaction between $N, \quad N$-diphenylthiourea and p-chloranil through a charge-transfer intermediate. J Chem Soc Perkin Trans 1999; 2(10): 2219-2223.

13. Khan NA, Chaudhary AB, Patro B, Rani AD. Analytical study of charge transfer complexation of rabeprazole with 2, 3-dichloro-5, 6-dicyano-1, 4-benzoquinone. Sci Asia 2009; 35(4): 365-371.

14. Saito G, Matsunaga $Y$. The electron acceptor strength of some substituted naphthoquinones. Bull Chem Soc Jpn 1971; 44: 1788-1791.

15. Darwish I, Abdel-Wadood H,Abdel-Latif N. Validated spectrophotometric and fluorimetric methods for analysis of clozapine in tablets and urine Annali di Chim 2005; 95(5): 345-356.

16. Taha A, Rücker G. Utility of pi-acceptors in alkaloid assay. Arch Pharm (Weinheim) 1977; 310(6): 485494.

17. Vogel Al.; Vogel's Textbook of Practical Organic Chemistry; England: Longman group UK Ltd; 1989.

18. Polarity Index. http://macro.Isu.edu/howto/solvents/ polarity\%20index.htm. Accessed Jan. 5, 2014.

19. Fidler AT, Baker EL, Letz RE. Neurobehavioural effects of occupational exposure to organic solvents among construction painters. Br J Ind Med 1987; 44(5): 292308.

20. Wennborg H, Bonde JP, Stenbeck M, Olsen J. Adverse reproduction outcomes among employees working in biomedical research laboratories. Scand $J$ Work Environ Health 2002; 28(1): 5-11.

21. Lindbohm ML, Taskinen H, Sallmen M, Hemminki $K$. Spontaneous abortions among women exposed to organic solvents. Am J Ind Med 1990; 17(4): 449463.

22. Wennborg H, Bodin L, Vainio H, Axelsson G. Pregnancy outcome of personnel in Swedish biomedical research laboratories. J Occup Environ Med 2000; 42(4): 438-446.

23. Kristensen $P$, Hilt $B$, Svendsen $K$, Grimsrud $T K$. Incidence of lymphohaematopoietic cancer at a university laboratory: a cluster investigation. Eur J Epidemiol 2008; 23(1): 11-15.

24. Darwish IA, Mahmoud AM, Al-Majed AR. A novel analytical approach for reducing the consumption of organic solvents in the charge transfer-based spectrophotometric analysis: application in the analysis of certain antihypertensive drugs Acta Pharm 2010; 60(4) 493-501.

25. ICH Guideline Q2 (R1). Validation of analytical procedures: text and methodology. The International Conference on Harmonization, London, UK, 2005. 